\title{
Mucosal production of uric acid by airway epithelial cells contributes to particulate matter-induced allergic sensitization
}

MJ Gold ${ }^{1}$, PR Hiebert ${ }^{2}$, HY Park ${ }^{3}$, D Stefanowicz ${ }^{2}$, A Le $^{2}$, MR Starkey ${ }^{4}$, A Deane $^{4}$, AC Brown ${ }^{4}$, G Liu $^{4}$, JC Horvat ${ }^{4}$, ZA Ibrahim ${ }^{5,6}$, MB Sukkar,6, PM Hansbro ${ }^{4}, C_{\text {C Carlsten }}^{2,7}$, S VanEeden ${ }^{2}$, DD Sin ${ }^{2}$, KM McNagny ${ }^{1,8}$, DA Knight ${ }^{4,9,10,11}$ and JA Hirota ${ }^{2,7,11}$

Exposure to particulate matter (PM), a major component of air pollution, contributes to increased morbidity and mortality worldwide. PM induces innate immune responses and contributes to allergic sensitization, although the mechanisms governing this process remain unclear. Lung mucosal uric acid has also been linked to allergic sensitization. The links among PM exposure, uric acid, and allergic sensitization remain unexplored. We therefore investigated the mechanisms behind PM-induced allergic sensitization in the context of lung mucosal uric acid. $\mathrm{PM}_{10}$ and house dust mite exposure selectively induced lung mucosal uric acid production and secretion in vivo, which did not occur with other challenges (lipopolysaccharide, virus, bacteria, or inflammatory/fibrotic stimuli). $\mathrm{PM}_{10}$-induced uric acid mediates allergic sensitization and augments antigen-specific T-cell proliferation, which is inhibited by uricase. We then demonstrate that human airway epithelial cells secrete uric acid basally and after stimulation through a previously unidentified mucosal secretion system. Our work discovers a previously unknown mechanism of air pollution-induced, uric acid-mediated, allergic sensitization that may be important in the pathogenesis of asthma.

\section{INTRODUCTION}

Epidemiology, clinical intervention, and animal model studies have defined the negative health consequences of air pollution on respiratory disease. ${ }^{1-4}$ Urban particulate matter (PM) is a major component of air pollution, and is broadly categorized as coarse $\left(\mathrm{PM}_{10}\right)$, fine $\left(\mathrm{PM}_{2.5}\right)$, or ultrafine $\left(\mathrm{PM}_{0.1}\right)$, based on mean particle size fractions that are $<10,2.5$, or $0.1 \mu \mathrm{m}$, respectively. PM varies based on geography, season, and proximity to roadways, and acts as a carrier for additional components of air pollution including polyaromatic hydrocarbons, elemental metals, and allergens. ${ }^{5,6}$ Deposition of PM with adsorbed air pollution components into the upper and lower airway respiratory mucosa $^{7}$ induces airway epithelial cell innate immune responses, ${ }^{8-12}$ which may be relevant in facilitating allergic sensitization and exacerbation of existing airway disease. ${ }^{4,12-14}$ We demonstrated that PM facilitates innate immune responses through the nucleotide-binding domain, leucine-rich repeat protein 3 inflammasome, ${ }^{8}$ but this innate immune sensor was not required for PM-facilitated allergic sensitization. ${ }^{12}$ Thus, the mechanism governing this PMinduced sensitization remains unknown.

The respiratory mucosa possesses several defenses against PM exposure and the oxidative effects of air pollution. ${ }^{8,11,15,16}$ These include tight junctions between epithelial cells,

${ }^{1}$ Biomedical Research Centre, University of British Columbia, Vancouver, British Columbia, Canada. ${ }^{2}$ James Hogg Research Centre, University of British Columbia, Vancouver, British Columbia, Canada. ${ }^{3}$ Division of Pulmonary and Critical Care Medicine, Department of Medicine, Samsung Medical Center, Sungkyunkwan University School of Medicine, Seoul, South Korea. ${ }^{4}$ Priority Research Centre for Asthma and Respiratory Disease, Hunter Medical Research Institute, University of Newcastle, Callaghan, Australia. ${ }^{5}$ Discipline of Pharmacy, Graduate School of Health, The University of Technology Sydney, Sydney, Australia. ${ }^{6}$ Woolcock Institute of Medical Research, Sydney Medical School, The University of Sydney, Sydney, Australia. ${ }^{7}$ Vancouver Coastal Health Research Institute, Vancouver General Hospital, Vancouver, British Columbia, Canada. ${ }^{8}$ Department of Medical Genetics, University of British Columbia, Vancouver, British Columbia, Canada. ${ }^{9}$ School of Biomedical Sciences and Pharmacy, University of Newcastle, Callaghan, Australia and ${ }^{10}$ Department of Anesthesiology, Pharmacology and Therapeutics, University of British Columbia, Vancouver, British Columbia, Canada. Correspondence: JA Hirota (jhirota@mail.ubc.ca)

${ }^{11}$ These authors were co-senior investigators in this work. 
expression of pattern recognition receptors linked to innate immune responses, production of antimicrobial peptides, and secretion of a complex and viscous mucus layer. The mucus layer contains a variety of protective innate immune mediators and antioxidants, including uric acid. Uric acid is generated by xanthine dehydrogenase $(\mathrm{XDH})$ as a metabolite of purine metabolism. ${ }^{17}$ Conversely, it is catabolized by uricase, which is restricted to the liver in most mammals including mice. ${ }^{18} \mathrm{In}$ humans, mutations over millions of years have lead to a nonfunctional uricase enzyme, resulting in elevations in circulating uric acid. ${ }^{19}$ In healthy humans, uric acid has been identified in upper and lower airway washings, ${ }^{20-22}$ suggesting that a secretory mechanism may exist; however, this has not been identified to date. Uric acid can promote either beneficial or harmful effects depending on its concentration and whether in solution or solid state. Soluble uric acid is a potent antioxidant and free radical scavenger. ${ }^{21,23}$ Conversely, at higher concentrations uric acid can precipitate into crystals that promote the activation of the nucleotide-binding domain, leucine-rich repeat protein 3 inflammasome and dendritic cells. ${ }^{24-26}$ Despite the clear beneficial and harmful roles that uric acid can play, how its levels are regulated in the respiratory mucosa under basal and stimulated conditions remains unknown.

Previous reports have demonstrated in mice that allergic sensitization to house dust mite (HDM) requires both Toll-like receptor 4 (TLR4) expression on airway epithelial cells and the presence of uric acid. ${ }^{27-29}$ We therefore hypothesized that (i) airway epithelial cells produce and secrete uric acid under basal and stimulated conditions and (ii) PM exposure induces respiratory mucosal uric acid production and secretion that is required for allergic sensitization.

We found that mucosal production of uric acid is induced by inhaled insults associated with allergic sensitization, and not by several other challenges. Uric acid was crucial in mediating the development of PM-facilitated allergic airway disease independent of TLR4, and regulated antigen-specific T-cell proliferation. The expression of $\mathrm{XDH}$ and a candidate uric acid transporter, multi-drug resistance protein 4 (MRP4), was identified and characterized in primary human airway epithelial cells and lung tissue. Inhibition of this transporter attenuates basal and stimulated uric acid production from airway epithelial cells, which was independent of cell death. Collectively, our results demonstrate that PM and HDM induce the production of uric acid through a novel airway mucosal secretion system that may have a key role in allergic sensitization.

\section{RESULTS}

Uric acid is selectively induced in mouse lungs by $\mathrm{PM}_{10}$ and HDM but not other challenges

We have shown that $\mathrm{PM}_{10}$ can facilitate allergic sensitization ${ }^{12}$ and can be found within airway epithelial cells in mouse lung following exposure. ${ }^{8}$ We therefore tested whether this occurs with the induction of uric acid. We exposed mice to a single intranasal dose of $\mathrm{PM}_{10}$ with and without uricase followed by bronchoalveolar lavage (BAL) $24 \mathrm{~h}$ later. $\mathrm{PM}_{10}$-induced uric acid production in the lung was inhibited by uricase (Figure 1a). Immunohistochemical staining for uric acid revealed robust positive staining in the airway epithelium under both basal and stimulated conditions (Figure 1b). We also observed staining in smooth muscle tissue in mouse lung. We next evaluated several other stimuli on lung uric acid production. Exposure to HDM induced similar levels of uric acid (Figure 1c) compared with $\mathrm{PM}_{10}$ (Figure 1a). In contrast, exposure to viral (influenza), bacterial (S. pneumoniae), or inflammatory/fibrotic (bleomycin) challenges had no effect on uric acid secretion (Figure 1d-f) despite inducing diverse lung pathologies (data not shown). Although exposure to lipopolysaccharide and ovalbumin (OVA) induced uric acid secretion in the lung, the levels did not reach statistical significance $(P>0.05$, Figure 1g). Thus, we conclude that uric acid is selectively induced in mouse lungs in response to $\mathrm{PM}_{10}$ and $\mathrm{HDM}$, which are environmental stimuli associated with allergic sensitization.

\section{Uric acid production in the lung during $\mathrm{PM}_{10}$ exposure facilitates allergic sensitization}

To examine the consequences of $\mathrm{PM}_{10}$-induced uric acid production on allergic sensitization, we used a model of mucosal sensitization and challenge using $\mathrm{PM}_{10}$ and OVA (Figure 2a). ${ }^{12}$ Concurrent exposure of mice to $\mathrm{PM}_{10} / \mathrm{OVA}$ induced allergic sensitization, as indicated by elevations in total BAL cells and eosinophils, OVA-specific immunoglobulins, lung Th2 cytokine gene expression, and goblet cell metaplasia (Figure 2b-q). Uricase instillation in the lungs during $\mathrm{PM}_{10} / \mathrm{OVA}$ co-exposure inhibited the development of an allergic phenotype with attenuation of all outcome measurements, with the exception of IFN $-\gamma$ gene expression in the lung (Figure 2b-q). OVA exposure in the absence of $\mathrm{PM}_{10}$ induced increases in markers of allergic sensitization, which were also attenuated by uricase treatment (Supplementary Figure S1 online).

\section{$\mathrm{PM}_{10}$-facilitated allergic sensitization is independent of TLR4}

It is possible that endotoxin present in our reagents could confound results obtained from a model of $\mathrm{PM}_{10}$-facilitated allergic sensitization to OVA with uricase treatment. Furthermore, reports have demonstrated that uric acid production relevant in allergic sensitization is downstream of TLR4. ${ }^{28,30}$ Using Tlr $4^{-1-}$ mice and our model of OVA/PM $\mathrm{P}_{10}$ co-exposure (Figure 2a), we demonstrate that $\mathrm{PM}_{10}$-facilitated allergic sensitization is independent of TLR4 (Figure 3). Furthermore, the activity of uricase in attenuating $\mathrm{PM}_{10}$-facilitated allergic sensitization is also independent of TLR4.

\section{$\mathrm{PM}_{10}$ induces an increase in lung group 2 innate lymphoid} cells which is not attenuated by uricase treatment

Recently, our group has linked group 2 innate lymphoid cells (ILC2s) to allergic sensitization at the respiratory mucosa surface. ${ }^{31}$ Our $\mathrm{PM}_{10} / \mathrm{OVA}$ model demonstrated an elevation in IL-33 gene expression, a key cytokine responsible for ILC2 maturation and function. We therefore pursued the possibility that $\mathrm{PM}_{10} / \mathrm{OVA}$ exposure was inducing ILC2s in our model in a 

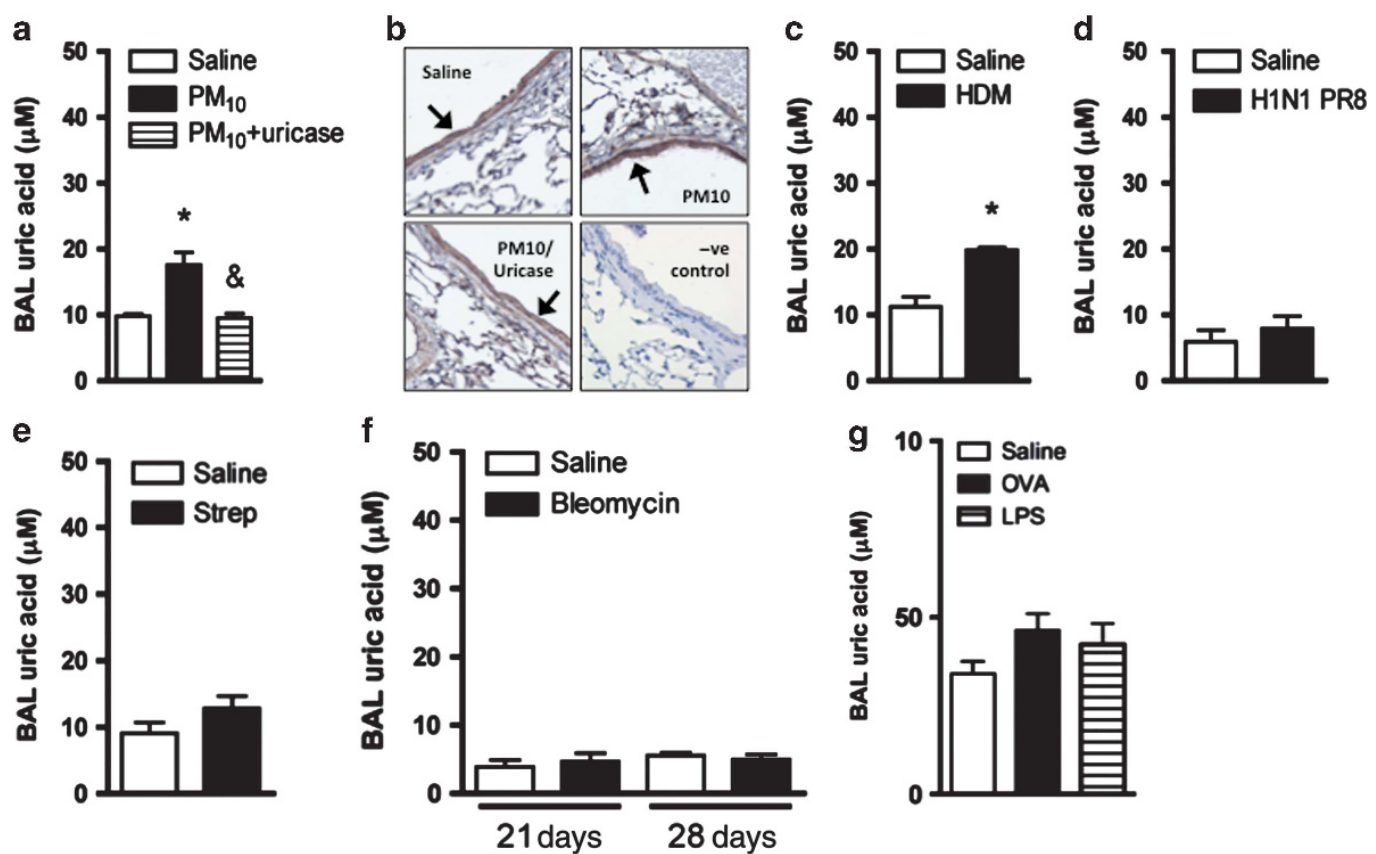

Figure 1 Urban particulate matter (PM) and house dust mite (HDM) allergen selectively induce mucosal production of uric acid in mouse lung. (a) Mouse bronchoalveolar lavage (BAL) uric acid levels following exposure to saline, $\mathrm{PM}_{10}$, or $\mathrm{PM}_{10}+$ uricase. (b) Immunohistochemical staining of uric acid in mouse lung following exposure to saline, $\mathrm{PM}_{10}$, or $\mathrm{PM}_{10}+$ uricase. Black arrows highlight uric acid staining in airway epithelial cells under basal and stimulated conditions. (c) Mouse BAL uric acid levels following exposure to saline or HDM. (d) Mouse BAL uric acid levels following exposure to saline or influenza virus infection. (e) Mouse BAL uric acid levels following exposure to saline or Streptococcus pneumoniae infection. (f) Mouse BAL uric acid levels following exposure to saline or bleomycin. (g) Mouse BAL uric acid levels following ovalbumin (OVA) or lipopolysaccharide (LPS) exposure. See Methods for details on all exposure protocols. ${ }^{*} P<0.05$ compared with saline exposure. ${ }^{\&} P<0.05$ compared with $\mathrm{PM}_{10}$ exposure. In vivo experiments were repeated in two independent trials with each trial $n=6$ for a total of 12 animals. Results are shown \pm s.e.m. s.e.m., standard error of the mean.

uric acid-dependent mechanism. $\mathrm{PM}_{10} / \mathrm{OVA}$ exposure induced a uric acid increase associated with an increase in lung ILC2s positive for intracellular IL-5 (Figure 4). Uricase treatment attenuated $\mathrm{PM}_{10} / \mathrm{OVA}$ induced uric acid, although no effect was observed on ILC2 numbers or IL-5 cytokine expression. The results suggest that ILC2s are not a key player mediating allergic sensitization in a model of $\mathrm{PM}_{10} / \mathrm{OVA}$ exposure.

\section{Uricase treatment attenuates antigen-specific CD4 T-cell proliferation}

Our observations that uricase inhibited in vivo $\mathrm{PM}_{10}$-facilitated allergic sensitization suggested that the downstream activity of $\mathrm{CD} 4+\mathrm{T}$ cells could also be modified. Thus, we examined the influence of $\mathrm{PM}_{10}$, and uricase treatment on CD4 + T-cell and regulatory T cell (Treg) activation. ${ }^{32,33}$ Proliferation of CD4 + $\mathrm{T}$ cells was restricted to the draining mediastinal lymph nodes and was induced by OVA/PM ${ }_{10}$ exposure, while uricase treatment attenuated this response (Figure $\mathbf{5 b}$ ). We quantified the percentage of carboxyfluorescein succinimidyl ester (CFSE)labeled $\mathrm{CD} 4+\mathrm{T}$ cells in each cycle of cell division and demonstrated that OVA/ $\mathrm{PM}_{10}$ exposure resulted in greater proliferation than OVA/ $\mathrm{PM}_{10}$ /uricase treatment (Figure 5c). Our results suggest that uricase treatment attenuates antigenspecific CD4 + T-cell proliferation. We next investigated the influence of uric acid on Tregs. OVA/ $\mathrm{PM}_{10}$ exposure induced an increase in exogenous (CFSE + ) Foxp3 + CD4 + Tregs from the adoptively transferred cells, which was not altered by uricase treatment (Figure 5d). No changes in endogenous $(\mathrm{CFSE}-)$ Foxp3 + CD4 + Tregs were observed following $\mathrm{OVA} / \mathrm{PM}_{10}$ exposure with or without uricase treatment (Figure 5e). In summary, these results suggest that $\mathrm{PM}_{10}$ exposure induces a selective, uricase-sensitive antigen-specific $\mathrm{CD} 4+\mathrm{T}$-cell proliferation that is independent of changes in Treg numbers.

\section{Human airway epithelial cells express a functional uric acid production and secretion system}

Uric acid has been detected in both lung ${ }^{22,28}$ and nasal ${ }^{21}$ washings in healthy humans, although the source(s) remain unknown. On the basis of these observations and our in vivo immunohistochemistry results (Figure 1b), we assessed whether human airway epithelial cells express a uric acid secretory system that is responsible for basal production that can be further activated by $\mathrm{PM}_{10}$. We found that unstimulated human airway epithelial cells produce uric acid and the enzyme responsible for its production, $\mathrm{XDH}$ (Figure 6a,b). Our observation of unstimulated uric acid production suggested that this could be an active process that is independent of cell death. In kidney tubular epithelial cells, MRP4 utilizes ATP to actively transport uric acid for secretion in the urine. ${ }^{34}$ We therefore evaluated MRP4 as a candidate uric acid transporter in airway epithelial cells and found its expression in both human airway epithelial primary cells and cell lines (Figure 6b). We subsequently performed confocal microscopy 
a

Day

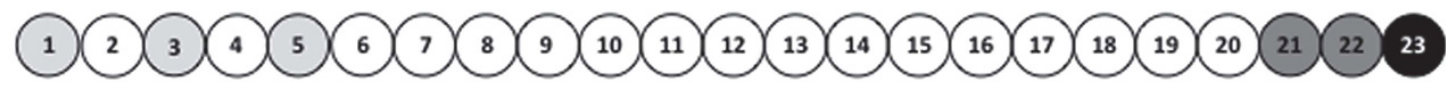

(i) Saline (ii) OVA/PM 10 (iii) OVA/PM 10 Uricase

OVA challenge

Killing
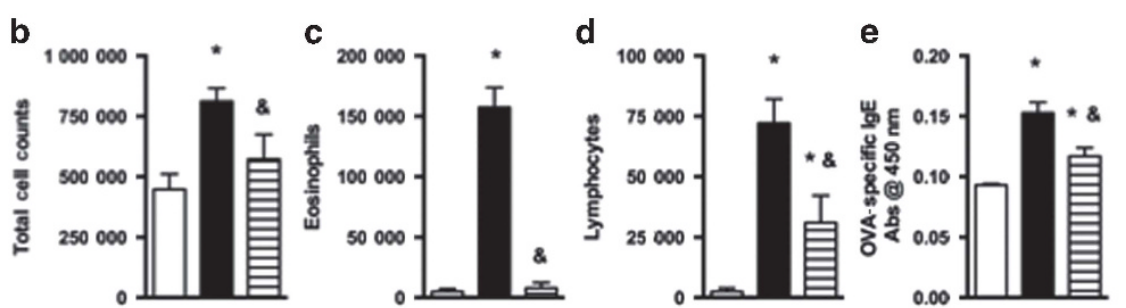

f
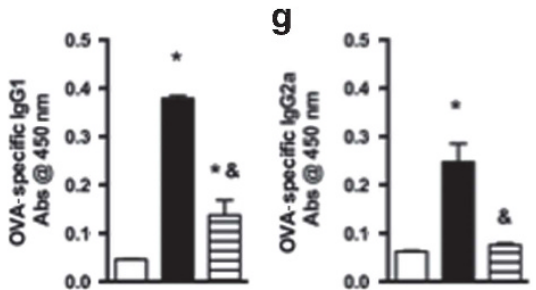

h
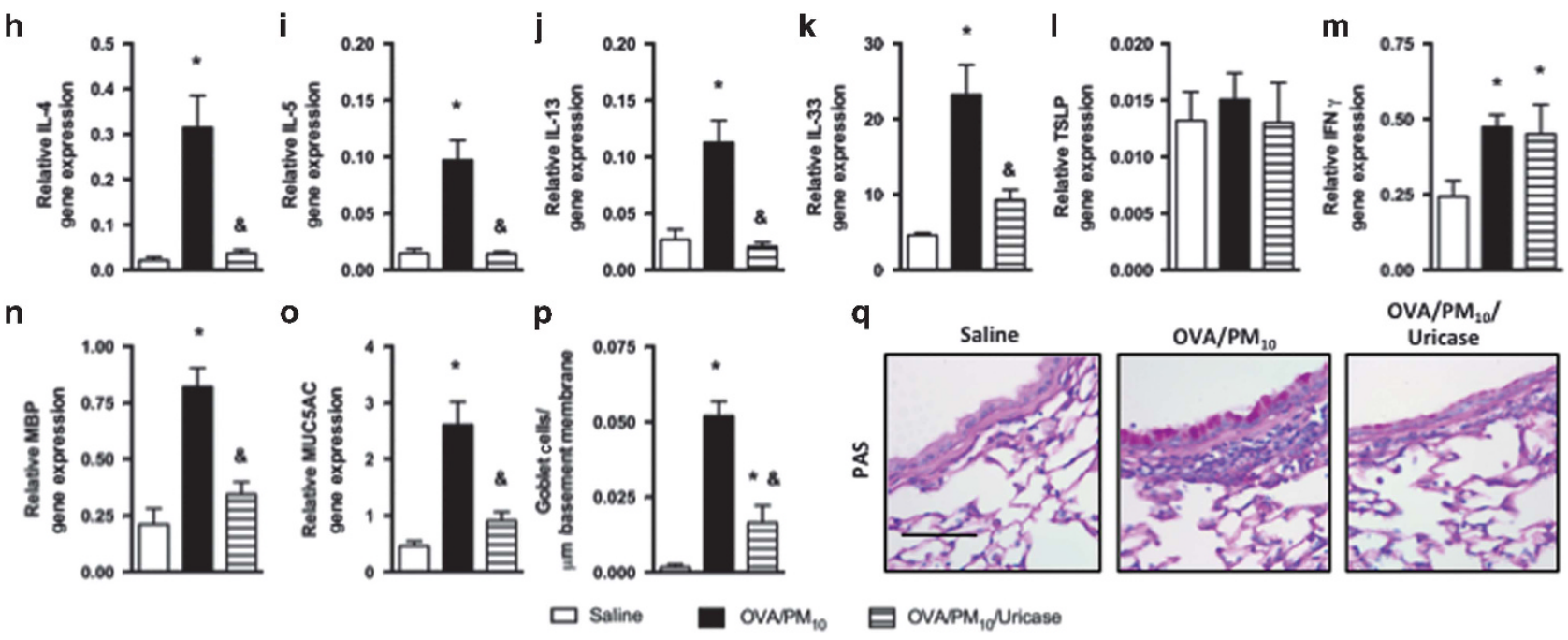

Figure $2 \mathrm{PM}_{10}$-facilitated allergic sensitization is inhibited by uricase in wild-type $\mathrm{C} 57 \mathrm{BI} / 6$ mice. Mice were exposed to saline, OVA/PM 10 , or OVA/PM 10 / uricase followed by challenges with OVA, and outcome measurements performed $24 \mathrm{~h}$ after the final exposure. (a) Animal exposure protocol. (b) Bronchoalveolar lavage (BAL) total cell counts. (c) BAL eosinophils. (d) BAL lymphocytes. (e) Serum OVA-specific lgE levels. (f) Serum OVA specificIgG1 levels. (g) Serum OVA-specific IgG2a levels. Gene expression in lung homogenates for (h) IL-4, (i) IL-5, (j) IL-13, (k) IL-33, (I) TSLP, (m) IFN- $\gamma$, (n) major basic protein (MBP), and (o) MUC5AC. (p) Goblet cell quantification. (q) Representative images of mouse airways stained with periodic acid Schiff for goblet cell quantification. ${ }^{\star} P<0.05$ compared with saline exposure. ${ }^{\circledR} P<0.05$ compared with $O V A / P M_{10}$ exposure. Experiments were repeated in two independent trials with each trial $n=5$ for a total of 10 animals. Results are shown \pm s.e.m. Scale bar represents $50 \mu \mathrm{m}$. OVA, ovalbumin; PM, particulate matter; s.e.m., standard error of the mean.

imaging for $\mathrm{XDH}$ and MRP4 protein expression in human airway epithelial cells (Figure 6c,d). XDH expression appeared to be diffuse throughout the cytoplasm of airway epithelial cells, whereas MRP4 expression was observed in punctate foci scattered throughout the cytoplasm. We confirmed in situ protein expression of $\mathrm{XDH}$ and MRP4 in human lungs by immunohistochemistry (Figure 6e). $\mathrm{XDH}$ staining was diffuse throughout all cell phenotypes in the airway epithelium, whereas MRP4 staining was restricted to basal cells. Collectively, these studies supported the hypothesis that human airway epithelial cells express a uric acid secretory system.

To determine whether $\mathrm{PM}_{10}$ or HDM impacted the expression of XDH and MRP4, we exposed airway epithelial cells to these insults and assessed gene expression. We demonstrate that $\mathrm{XDH}$ and MRP4 gene expression is not changed following either environmental exposure in HBEC-6KT human airway epithelial cells (Figure 7a). We next determined whether the uric acid secretory system was functional, by exposing human airway epithelial cells to $\mathrm{PM}_{10}$ and measuring uric acid production. Control experiments with $\mathrm{PM}_{10}$ and uric acid in the absence of cells demonstrated an interaction between these components resulting in a compromised ability to detect a uric acid signal (Supplementary Figure S2). Our $\mathrm{PM}_{10}$ (ref. 35) contains iron, which may be an important confounding variable as this metal can chelate uric acid, ${ }^{36}$ potentially impacting our method of detection in in vitro experimental systems. We therefore used HDM as a trigger (Figure 1c). ${ }^{28}$ 

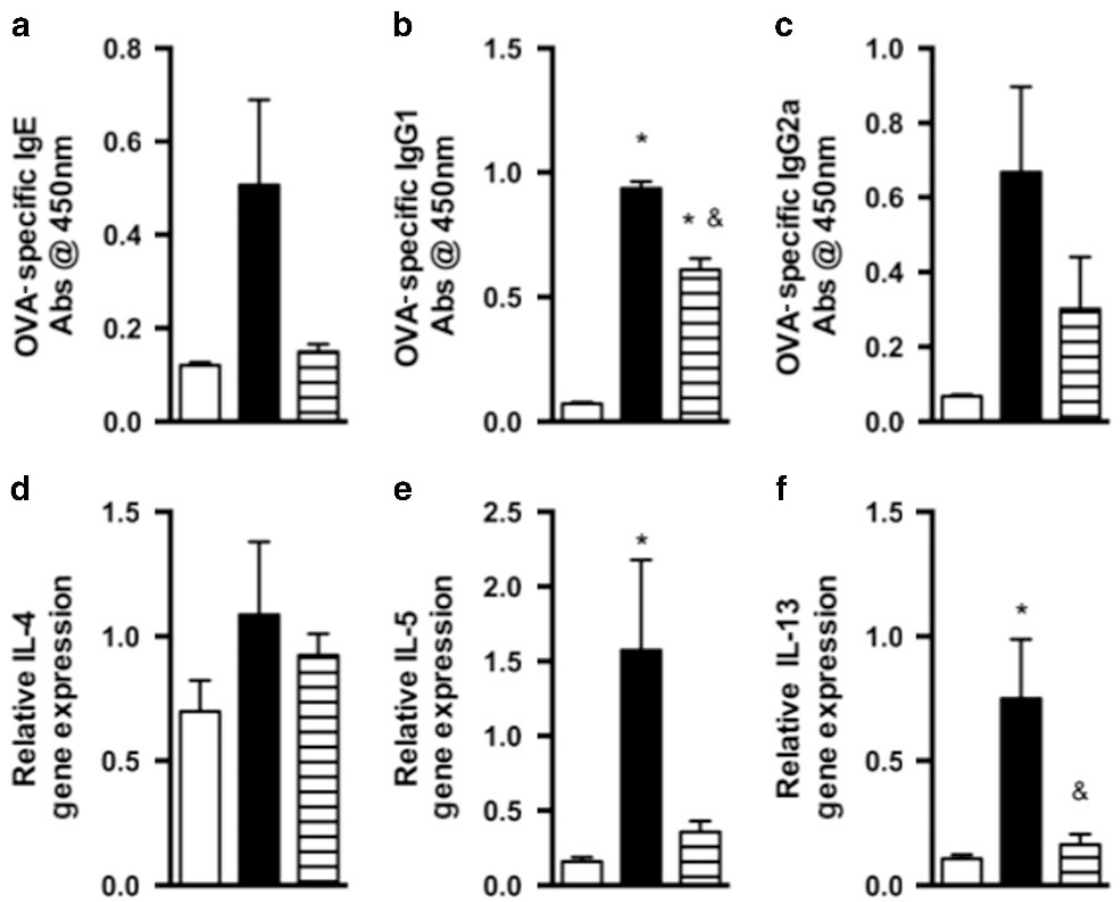

e

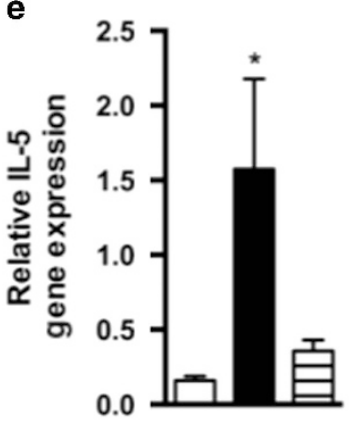

$\mathbf{f}$
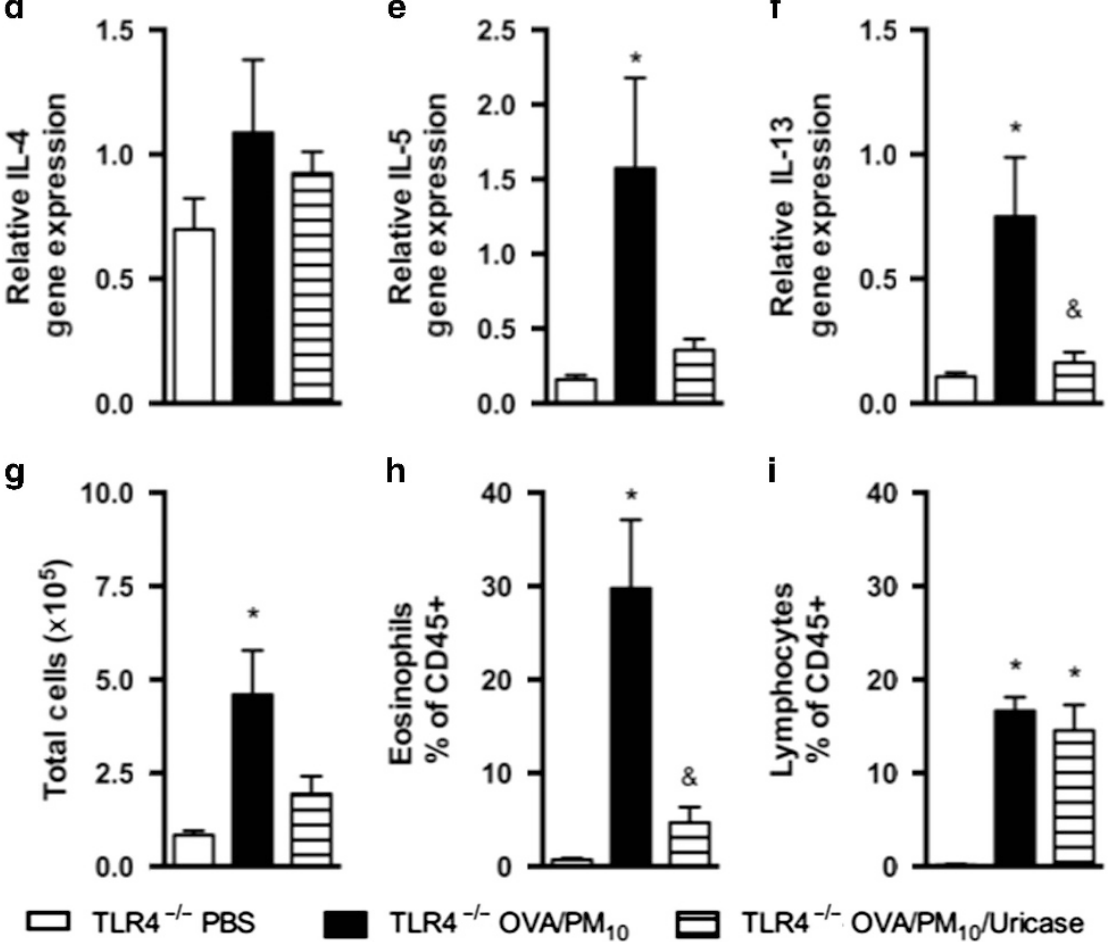

h
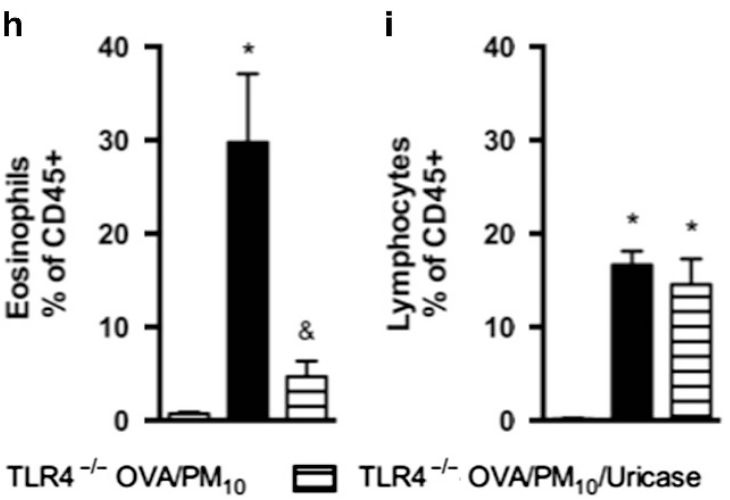

Figure $3 \mathrm{PM}_{10}$-facilitated allergic sensitization and uricase activity is TLR4 independent. TIr4 ${ }^{-1-}$ mice were exposed to saline, OVA/PM 10 , or OVA/ $\mathrm{PM}_{10}$ /uricase followed by challenges with OVA, and outcome measurements performed $24 \mathrm{~h}$ after the final exposure. (a) Serum OVA-specific IgE levels. (b) Serum OVA-specific-IgG1 levels. (c) Serum OVA-specific IgG2a levels. Gene expression in lung homogenates for (d) IL-4, (e) IL-5, (f) IL-13, (g) bronchoalveolar lavage (BAL) total cell counts, (h) BAL eosinophils, and (i) BAL lymphocytes. ${ }^{\star} P<0.05$ compared with saline exposure. ${ }^{\&} P<0.05$ compared with OVA/PM 10 exposure. $n=5$ for each group. Results are shown \pm s.e.m. OVA, ovalbumin; PM, particulate matter; s.e.m., standard error of the mean; TLR4, Toll-like receptor 4.

HDM exposure resulted in a trend for a time-dependent increase in uric acid production from primary human airway epithelial cells (Figure 7b). To implicate MRP4 as the functional transporter for uric acid, we used MK-571, a cysteinyl leukotriene receptor antagonist, that also blocks MRP4 function. ${ }^{37}$ Exposure to HDM for $24 \mathrm{~h}$ induced a significant uric acid production in HBEC-6KT human airway epithelial cells (Figure 7c) and this was independent of cell death (Figure 7d). Moreover, MK-571 treatment attenuated both basal and HDM-induced uric acid production in HBEC6KT human airway epithelial cells (Figure 7c). To confirm these findings, we used different classes of pharmacological compounds that also block MRP4 function..$^{38}$ Both losartan, an angiotensin II receptor antagonist, and indomethacin, a nonselective cyclooxygenase antagonist, inhibited HDM-induced uric acid production in HBEC-6KT (Figure 7e,f). To further confirm the functional properties of MRP4 in human airway epithelial cells, we performed experiments probing cyclic AMP secretion in HBEC-6KT human airway epithelial cells. Cyclic AMP, like uric acid, is a known endogenous substrate for MRP4. ${ }^{38}$ We demonstrate that HBEC-6KT human airway epithelial cells are capable of secreting cyclic AMP (Supplementary Figure S3A) and this is inhibited with MK-571 $(P<0.05)$. Interestingly, however, neither $\mathrm{PM}_{10}$ nor $\mathrm{HDM}$ induced cyclic AMP secretion in HBEC-6KT human airway epithelial cells (Supplementary Figure S3B).

Previous studies suggest that uric acid is upstream of IL- $1 \alpha$ and HMGB1 cascade and that these mediators temporally precede elevations of IL-33 and TSLP during allergic sensitization. ${ }^{30,39}$ We therefore examined whether uric acid alone could 

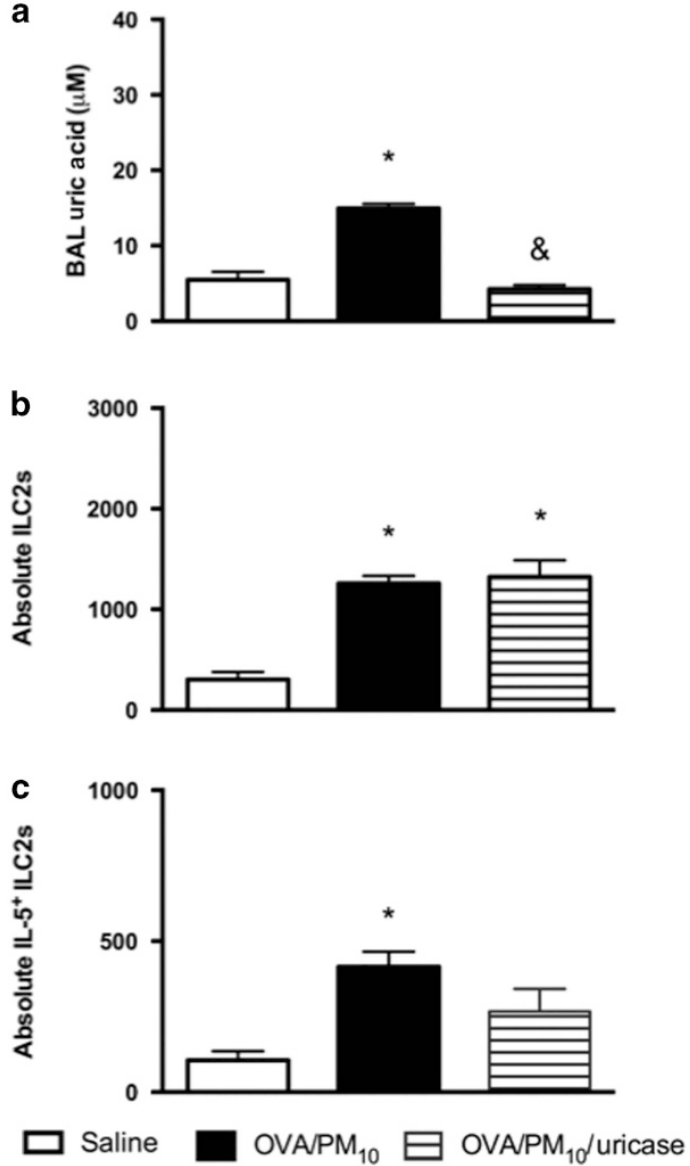

Figure $4 \quad \mathrm{PM}_{10}$ induces an increase in lung group 2 innate lymphoid cells (ILC2s), which is not attenuated by uricase treatment. (a) Mouse bronchoalveolar lavage (BAL) uric acid levels following exposure to saline, $\mathrm{PM}_{10} / \mathrm{OVA}$, or $\mathrm{PM}_{10} / \mathrm{OVA} /$ uricase. (b) Absolute number of lung ILC2s (Lineage-CD45 + CD90.2 + CD25 + Sca1 + ST2 + viable cells) or (c) IL-5 + ve ILC2s following 5 days of exposure to saline, $\mathrm{PM}_{10} / \mathrm{OVA}$, or $\mathrm{PM}_{10} / \mathrm{OVA}$ /uricase. ${ }^{*} P<0.05$ compared with saline exposure.

${ }^{\&} P<0.05$ compared with $\mathrm{PM}_{10} / \mathrm{OVA}$ exposure. Experiments were repeated in two independent trials with each trial $n=4-5$ for a total of 10 animals. Results are shown \pm s.e.m. OVA, ovalbumin;

PM, particulate matter; s.e.m., standard error of the mean.

induce cytokine production from airway epithelial cells. Exposure of primary human airway epithelial cells to soluble uric acid did not induce any production of either IL- $1 \alpha$ or HMGB1 above control (Supplementary Figure S4). In experiments with airway epithelial cells exposed to HDM that triggered detectable uric acid, we were unable to detect any IL-33 and TSLP in any control or experimental conditions (data not shown).

Collectively, our data support the presence and function of an active MRP4-mediated uric acid secretion system in human airway epithelial cells, which may be a mechanistic pathway for uric acid production in vivo in response to $\mathrm{PM}_{10}$ and allergens.

\section{DISCUSSION}

We demonstrate for the first time that air pollution $\mathrm{PM}_{10}$ induces uric acid production in the respiratory mucosa. We found that airborne allergens such as HDM also induce uric a

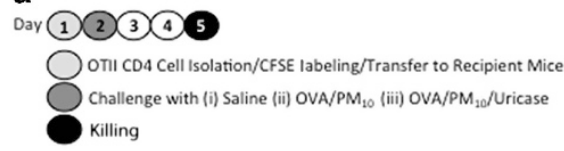

b

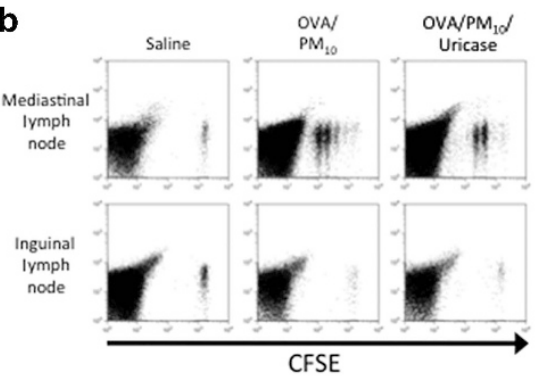

C
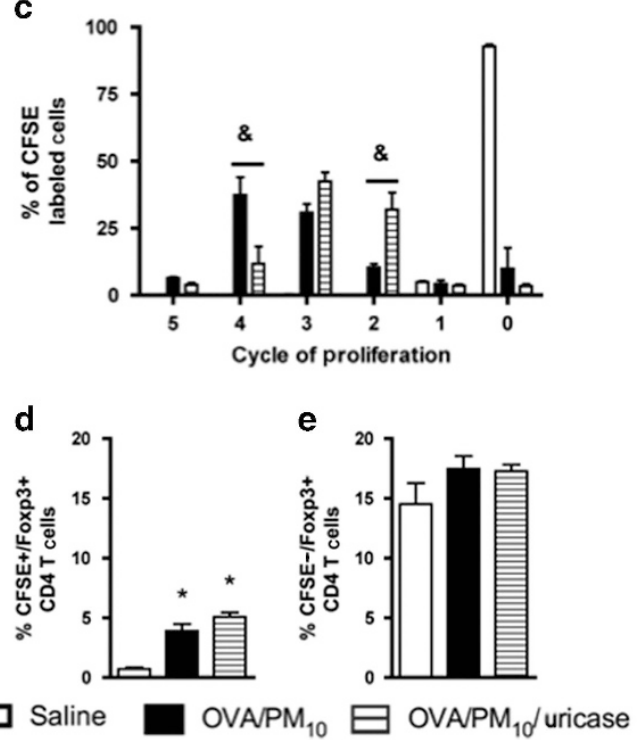

Figure 5 Uricase treatment attenuates in vivo antigen-specific CD4 $\mathrm{T}$-cell proliferation in response to $\mathrm{PM}_{10}$ exposure, independent of changes in regulatory $\mathrm{T}$ cell (Treg) number. (a) Animal exposure protocol.

(b) Representative flow-cytometry plots of lung draining mediastinal lymph node and control inguinal lymph node for carboxyfluorescein succinimidyl ester (CFSE)-labeled CD4 T cells from saline (left), OVA/PM 10 (center), and OVA/PM 10 /uricase (right) challenged animals. Control non-draining inguinal lymph nodes are shown below. (c) Quantification of CFSE-labeled CD4 T-cell proliferation in mediastinal lymph nodes. (d) Quantification of CD4 + Foxp3 + CFSE + cells (transferred exogenous cells) in mediastinal lymph nodes. (e) Quantification of CD4 + Foxp3 + cells (endogenous cells) in mediastinal lymph nodes. ${ }^{*} P<0.05$ compared with saline exposure. ${ }^{\&} P<0.05$ compared with $O V A / P M_{10}$ exposure. Experiments were repeated in two independent trials with each trial $n=4-5$ for a total of 8-10 animals. Results are shown \pm s.e.m. OVA, ovalbumin; PM, particulate matter; s.e.m., standard error of the mean.

acid production, while other disease triggers including viral or bacterial infection and fibrotic stimuli do not. Further, uric acid secretion occurs at least in part, through a previously uncharacterized mucosal uric acid secretion system in airway epithelial cells. Thus, air pollution and allergens may induce uric acid production that facilitates allergic sensitization and asthma pathogenesis. Our work sets the stage for further investigation of the clinical relevance of the respiratory 

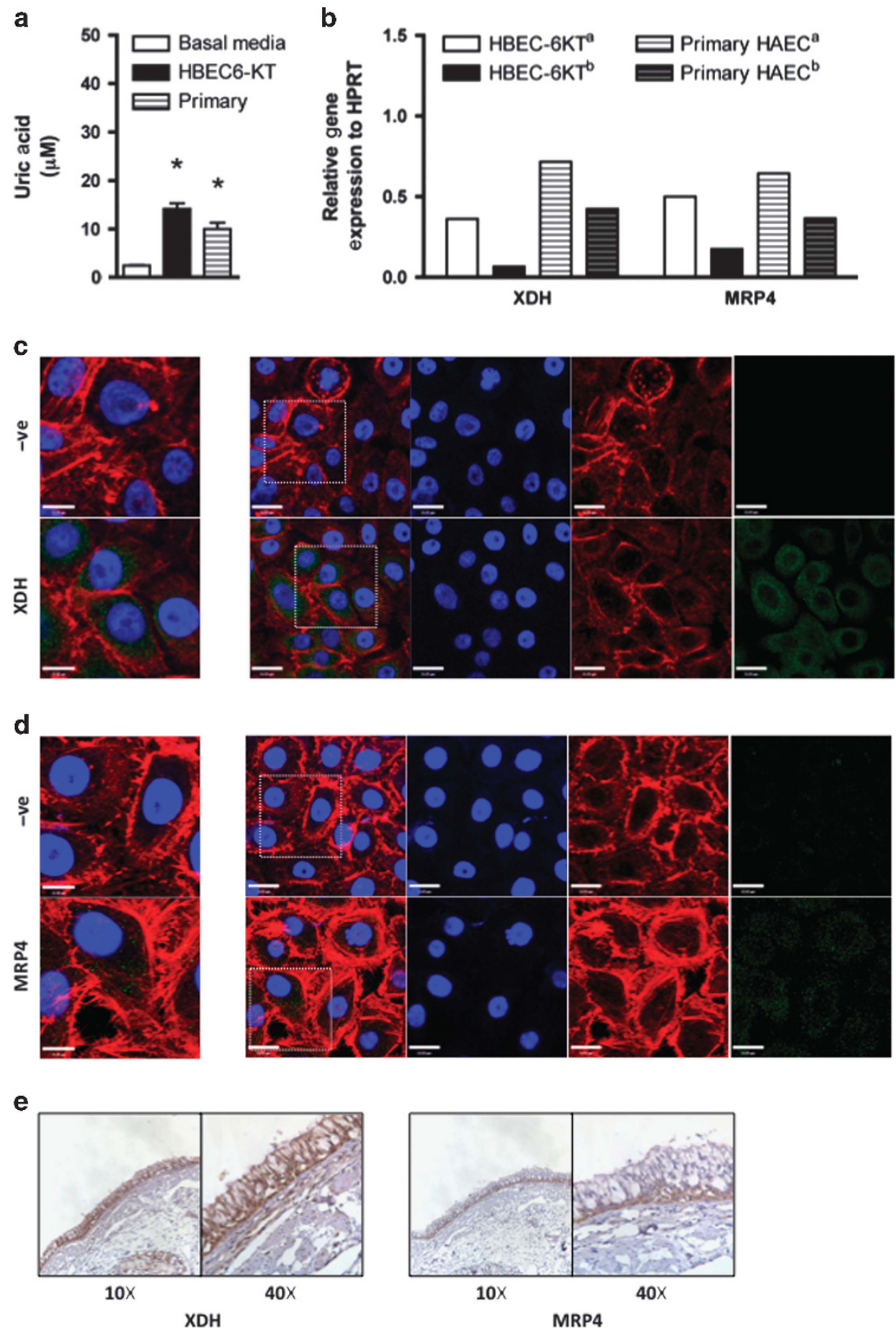

Figure 6 Airway epithelial cells express a uric acid production and secretory system. (a) Basal secretion of uric acid from human HBEC-6KT airway epithelial cells and primary airway epithelial cells relative to basal growth media. (b) Quantitative RT-PCR relative gene expression of xanthine dehydrogenase (XDH) and multi-drug resistance protein 4 (MRP4) in human airway epithelial cells. Two independent HBEC-6KT cultures were analyzed $\left(\mathrm{HBEC}-6 \mathrm{KT}^{\mathrm{a}}\right.$ and ${ }^{\mathrm{b}}$ ) and two independent primary human airway epithelial cells (HAEC ${ }^{\mathrm{a}}$ and ${ }^{\mathrm{b}}$ ) were analyzed. Confocal microscopy imaging of XDH (c) and MRP4 (d) immunocytochemistry on HBEC-6KT cultures. Blue =DAPI/nuclei, Red = Phalloidin-labeled actin, Green $=$ XDH or MRP4. (e) Representative XDH and MRP4 immunohistochemistry of healthy subject human airways showing in situ protein expression (brown) in airway epithelium. ${ }^{*} P<0.05$ compared to basal media control.

epithelial cell uric acid secretion system in lung health and disease.

A link has been recently established between uric acid production and allergic sensitization in models of intraperitoneal injection of OVA/alum and mucosal instillation of HDM. ${ }^{28}$ Additional reports show that uric acid crystals influence dendritic cells in vitro and allergic sensitization in vivo. ${ }^{25,26,28}$ These observations led us to hypothesize that mucosal uric acid production is the underpinning mechanism of $\mathrm{PM}_{10}$-facilitated allergic sensitization. Our results demonstrate that $\mathrm{PM}_{10}$ can indeed induce uric acid production to levels similar to those reported for $\mathrm{HDM},{ }^{28}$ and that the airway epithelium is a significant source. Expression of uric acid was also observed in smooth muscle, but at levels much lower than in airway epithelium. This suggests that the airway epithelium is likely the dominant source of uric acid in lung tissue. 

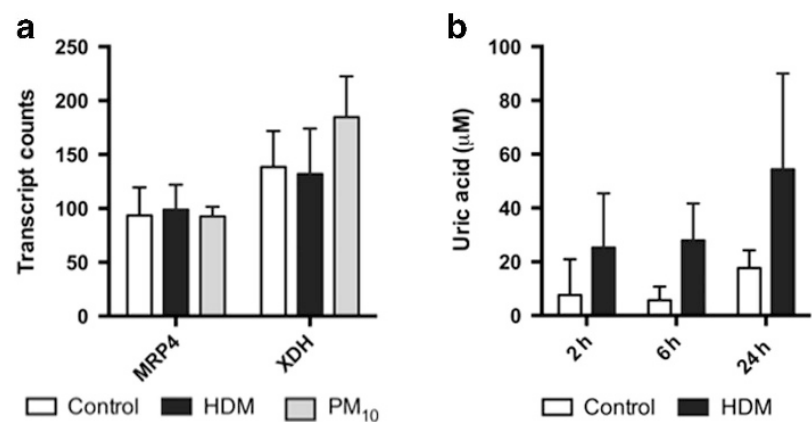

c

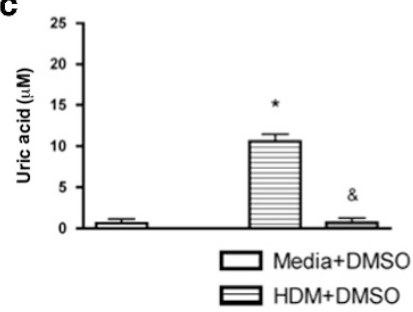

d

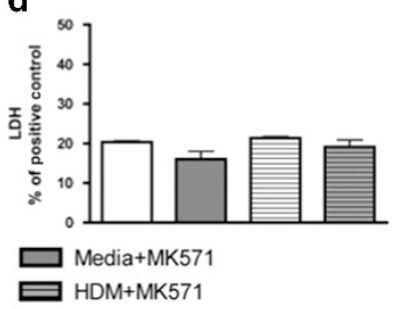

e

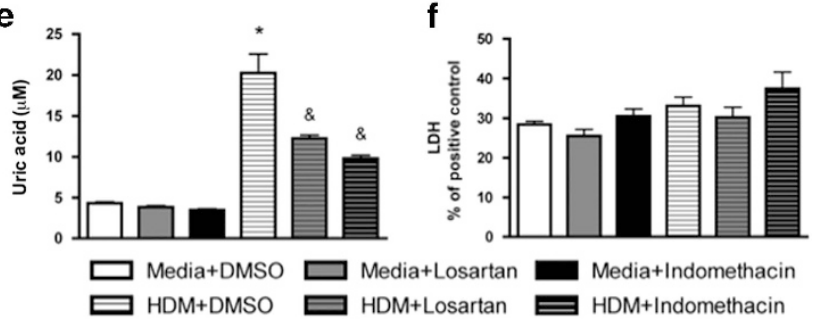

Figure 7 Airway epithelial cells express a functional uric acid production and secretory system that operates independent of changes in lactate dehydrogenase (LDH) secretion. (a) Gene expression by nanoString nCounter analysis for transcript quantification of multi-drug resistance protein 4 (MRP4) and xanthine dehydrogenase (XDH) in human airway epithelial cells following $\mathrm{PM}_{10}$ or HDM exposure for $24 \mathrm{~h}$. (b) Time course for HDM-induced uric acid production from primary human airway epithelial cells $(n=3)$. (c) Influence of MK-571 inhibition (20 $\mu \mathrm{M})$ of MRP4 on HDM-induced uric acid production by HBEC-6KT human airway epithelial cells. (d) Cell-culture supernatant LDH concentration following MK-571 inhibition of MRP4 and HDM exposure. (e) Independent experiments examining the influence of losartan $(10 \mu \mathrm{M})$ and indomethacin $(10 \mu \mathrm{m})$ inhibition of MRP4 on HDM-induced uric acid production by human airway epithelial cells. (f) Cell-culture supernatant LDH concentration following losartan or indomethacin inhibition of MRP4. ${ }^{*} P<0.05$ as compared with basal media, non-asthmatic, or media + DMSO control. ${ }^{\&} P<0.05$ as compared with the corresponding vehicle (DMSO) control. In vitro experiments were repeated three times with $n=3$ each time unless otherwise noted. Results are shown \pm s.e.m. HDM, house dust mite; PM, particulate matter; s.e.m., standard error of the mean.

In contrast to $\mathrm{PM}_{10}$ and $\mathrm{HDM}$ exposures, which are associated with allergic sensitization, exposure to insults that lead to other clinically relevant forms of lung inflammation, innate immune responses, and pathology did not induce uric acid release. Exposure to influenza, S. pneumoniae, or bleomycin have all been associated with cell death, ${ }^{40-44}$ but we did not observe an increase in lung uric acid in any of these models. Our data provide strong evidence that a selective production of epithelial uric acid occurs in response to air pollution or allergen and that lung pathology associated with cell death does not lead to sustained, significant, elevations in uric acid.
Pulmonary uric acid production has been linked to Th2skewed allergic sensitization to $\mathrm{HDM},{ }^{28}$ although the mechanism of its release and/or cellular source has not been clearly defined. We demonstrate that $\mathrm{PM}_{10}$ can induce similar increases in lung uric acid production, while we, and others, have reported the ability of $\mathrm{PM}_{10}$ to facilitate Th2-skewed allergic sensitization. ${ }^{12-14}$ We therefore reasoned that an intervention strategy that inhibited $\mathrm{PM}_{10}$-induced uric acid in the respiratory mucosa should be effective in preventing allergic sensitization. To test this, we used intranasal uricase treatment to selectively reduce uric acid in the mucosal environment during the sensitization phase of an OVA/ $\mathrm{PM}_{10}$ co-exposure model. ${ }^{12}$ Uricase treatment completely attenuated allergic sensitization and the development of Th2-skewed immune responses. The concentrations of uric acid detected in our in vivo studies $\left(10-20 \mu \mathrm{M}\right.$ or $\left.1-2 \mu \mathrm{g} \mathrm{ml}^{-1}\right)$ are well below the solubility threshold $\left(70 \mu \mathrm{g} \mathrm{ml}^{-1}\right)$, suggesting that crystal formation in the lung is likely not the mechanism behind the response to $\mathrm{PM}_{10}$. Although we currently cannot rule out local crystal formation in microenvironments, it has been reported that formation of uric acid crystals at supersaturating concentrations requires more than a week. ${ }^{45}$ On the basis of our data and current knowledge, the downstream consequences of $\mathrm{PM}_{10}$-induced uric acid production may be more closely linked to the soluble form of this of this molecule. Collectively, our data show that mucosal production of uric acid occurs in response to $\mathrm{PM}_{10}$ and this is a critical molecule required for $\mathrm{PM}_{10}$-facilitated allergic sensitization.

To pursue the possibility that uricase treatment could have off-target effects independent of breaking down uric acid, additional experiments were performed with added controls. In our models, $\mathrm{PM}_{10}$ exposure induced a significant amount of lung uric acid (Figure 1a, $P<0.05$ ), while a trend for increased uric acid was observed for OVA exposure (Figure 1g, $P>0.05$ ). Uricase treatment in both the OVA alone and OVA $+\mathrm{PM}_{10}$ exposure groups prevented allergic sensitization. The mechanism responsible for this is likely attributable to the breakdown of uric acid induced by $\mathrm{PM}_{10}$ and OVA, although the low levels of uric acid induced by OVA allude to the potential that uricase may also be having some off-target effects that are capable of suppressing Th2 immunity, independent of uric acid. ${ }^{46}$ Several mouse studies examining lung inflammation and remodeling have used uricase as a preclinical strategy to attenuate levels of lung uric acid. ${ }^{28,47,48}$ We have used a similar strategy and demonstrate the ability of uricase to break down uric acid in BAL fluid of $\mathrm{PM}_{10}$-challenged mice (Figure 1a). Commercial uricase used by these studies contains endotoxin $\left(841 \mathrm{EU} \mathrm{ml}^{-1}\right)$, which may provide a confounding factor for data interpretation. Furthermore, reports have demonstrated that uric acid production relevant in allergic sensitization is downstream of TLR4. ${ }^{28,30}$ We addressed these issues by performing experiments in Tlr $4^{-1-}$ mice and demonstrate that both $\mathrm{PM}_{10}$-facilitated allergic sensitization to OVA and uricase attenuation of this process are independent of TLR4. Alternative off-target effects of uricase ${ }^{49}$ and TLR4independent pathways leading to uric acid production may 
exist, but a complete characterization of these possibilities is beyond the scope of the present paper.

Elevations in airway epithelial cell-derived cytokines including IL-33, TSLP, and IL-25 have been linked to ILC2s development and function. ${ }^{31}$ To investigate whether ILC2s were induced in our $\mathrm{PM}_{10} / \mathrm{OVA}$ exposure model, we performed flow-cytometric analysis of ILC2 population number and expression of IL-5. We demonstrate that $\mathrm{PM}_{10} / \mathrm{OVA}$ exposure induces an expansion of lung ILC2s that are positive for IL-5, but these are not influenced by uricase treatment, despite changes in lung uric acid levels. Collectively, these data suggest that ILC2s are induced in our model of $\mathrm{PM}_{10} / \mathrm{OVA}$ exposure, but they are not key players in the induction of allergic sensitization that is attenuated with uricase treatment.

A possible interpretation of our findings is that soluble uric acid attenuates dendritic cell activation upon $\mathrm{PM}_{10}$ exposure, impairing the development of Tregs or Th1/Th17-skewed inflammatory responses, resulting in Th2-skewed allergic sensitization. ${ }^{33,50,51}$ However, uricase did not change lung IFN- $\gamma$ (Th1) responses or Treg numbers, suggesting that this is not the case. We therefore explored the alternate possibility that uric acid acts directly on $\mathrm{T}$ cells to induce proliferation as has been reported. ${ }^{32}$ Adoptive transfer experiments using CFSE-labeled antigen-specific OTII CD4 $+\mathrm{T}$ cells suggest that uricase treatment attenuates proliferation of these cells, although it remains unknown whether this is a direct or indirect effect of uric acid. It is possible that uric acid influences OTII $\mathrm{CD} 4+\mathrm{T}$-cell proliferation directly by acting on $\mathrm{T}$ cells or indirectly by acting on dendritic cells, independent of Treg cells. Future in vitro and in vivo studies using direct uric acid treatment on $\mathrm{T}$ cells in culture or adoptive transfer of antigenpulsed dendritic cells, respectively, would extend our original observations.

Uric acid has been detected in nasal and airway washings of healthy human subjects, although the mechanism governing its production and secretion remains uncharacterized. ${ }^{21,22} \mathrm{XDH}$ is the enzyme responsible for the endogenous production of uric acid, and our data identify the expression of this enzyme in airway epithelial cells. We then focused on possible mechanisms for uric acid secretion based on the previous analyses of uric acid transporters in kidney tubular epithelial cells. ${ }^{34,52}$ Of the several known uric acid transporters, only MPR4 expression was reported to be restricted to the apical side of kidney tubular epithelial cells, ${ }^{34}$ and so we focused on this candidate. We demonstrate that MRP4 is expressed in human airway epithelial cells in vitro and in situ and its expression is not impacted by either $\mathrm{PM}_{10}$ or HDM exposure. Our findings confirm the only other report demonstrating MRP4 protein expression in human airway epithelial cells, ${ }^{37}$ although the function this group attributed to this protein was for prostaglandin transport.

We next sought to determine whether uric acid detected in vivo following $\mathrm{PM}_{10}$ exposure was produced from airway epithelial cells using this production and secretion system. In control experiments, we spiked known concentrations of uric acid with the dose of $\mathrm{PM}_{10}$ used for our in vitro studies
(Supplementary Figure S2). ${ }^{8}$ Unfortunately, $\mathrm{PM}_{10}$ interfered with detection of uric acid, precluding its use in subsequent in vitro experiments. The mechanism of how $\mathrm{PM}_{10}$ interferes with uric acid detection remains unknown and may involve adsorption of uric acid to the $\mathrm{PM}_{10}$, oxidation of uric acid by $\mathrm{PM}_{10}$, or $\mathrm{PM}_{10}$ interference with the uric acid assay chemistry. Iron content in $\mathrm{PM}_{10}$ (ref. 35) may be an important confounding variable as this metal can chelate uric acid, ${ }^{36}$ potentially impacting our method of detection in our in vitro experimental system. Since we (Figure 1c), and others, ${ }^{28}$ have shown that HDM induces uric acid production in mouse lungs, we exposed human airway epithelial cells to HDM and observed increased uric acid release. Previous studies have implicated cell death as a source of uric acid release while not addressing the possibility of active cell processes involving transporters. ${ }^{26,45}$ To further support active transport as the mechanism of uric acid release in the respiratory mucosa, we performed an intervention study with MK-571, which inhibits MRP4 activity. ${ }^{37}$ MK-571 attenuated basal and HDM-induced uric acid production by airway epithelial cells, which was independent of changes in lactate dehydrogenase (LDH) levels, further suggesting an active release mechanism that is independent of cell death. To selectively interrogate the role of MRP4 in transport of uric acid, we attempted siRNA experiments. We were unable to achieve significant knockdown even after $48 \mathrm{~h}$ exposure to a cocktail of siRNA (data not shown). Accordingly, we used a pharmacological approach with several different classes of compounds reported to inhibit MRP4 activity. ${ }^{38}$ Exposure to the clinically used drugs losartan and indomethacin ${ }^{38}$ also inhibited MRP4-mediated uric acid release, further supporting a role for this transporter in human airway epithelial cells.

Additional experiments were performed to determine whether uric acid operated upstream of IL-1 $\alpha$, HMGB1, IL-33, and TSLP, as these immune mediators have been implicated in bridging innate and adaptive immune responses. ${ }^{30,39}$ Exposure of primary human airway epithelial cells directly to uric acid failed to induce production of any of these mediators in our model system. Collectively, our results demonstrate that uric acid production and transport through MRP4 does not result in autocrine or paracrine signaling and production of IL-1 $\alpha$, HMGB1, IL-33, or TSLP from human airway epithelial cells.

A limitation of our study is that we have not demonstrated that in vivo production and transport of uric acid in response to $\mathrm{PM}_{10}$ and HDM exposure is mediated through the same mechanism, despite our data and that of others showing uric acid expression in airway epithelial cells in mice. ${ }^{28}$ For our in vitro studies, we used HDM as a stimulus for uric acid production and transport in airway epithelial cells as $\mathrm{PM}_{10}$ interfered with measurements. Our data clearly demonstrate that airway epithelial cells can produce and transport uric acid through MRP4. Further studies are required to confirm whether the mechanisms by which $\mathrm{PM}_{10}$ and HDM stimulate uric acid production and secretion are conserved.

In summary, our studies demonstrate that (i) mucosal production of uric acid is selective for inhaled insults that are 
associated with allergic sensitization, (ii) in vivo mucosal production of uric acid is crucial in mediating the development of $\mathrm{PM}_{10}$-facilitated allergic airway disease and the regulation of antigen-specific T-cell proliferation, and (iii) the airway epithelium is the primary source of active uric acid production and secretion. To our knowledge, this study presents the first evidence of a uric acid transport system in the human airway epithelium. Collectively, our work highlights the importance of air pollution- and allergen-induced mucosal production of uric acid in the context of allergy and asthma and establishes a foundation to pursue the clinical relevance of the respiratory epithelial cell uric acid secretion system in lung health and disease.

\section{METHODS}

Mice. Female C57BL/6 mice 6-8 weeks of age were purchased from Jackson Laboratories (Bar Harbor, ME) for all $\mathrm{PM}_{10}$ and HDM exposure experiments, or from the Central Animal House at the University of Newcastle for S. pneumoniae, and bleomycin exposure experiments. For influenza H1N1 A/PR/8/34 exposure, wild-type $\mathrm{BALB} / \mathrm{c}$ mice aged 6-8 weeks of age were purchased from the Central Animal House at the University of Newcastle. Tlr $4^{-1-}$ mice were on a $\mathrm{C} 57 \mathrm{Bl} / 6$ background and bred at the UBC Biomedical Research Facility.

$\mathbf{P M}_{10}$ characteristics. We used EHC93 $\mathrm{PM}_{10}$ collected by Health Canada as described previously, ${ }^{6,35}$ which is comparable to National Institute for Standards and Technology standard reference material (NIST-SRM)-1649.6,35

Reagents. Human airway epithelial cell lines and primary cells were grown as described previously. ${ }^{8}$ Chicken egg white OVA grade V, uricase, and uric acid were purchased from Sigma (Oakville, Ontario Canada). PE-conjugated CD25 (PC61.5), Sca-1 (D7), APC-conjugated IL-5, and APC-efluor780 efluor650-conjugated CD90.2 (53-2.1) were purchased from eBioscience (San Diego, CA). FITC-conjugated ST2 (DJ8) was purchased from MD Bioproducts (St Paul, MN). Pacific Blue-conjugated CD45 (I3/2) was produced in-house. Intracellular cytokine staining was performed with the Cytofix/Cytoperm kit (BD Bioscience, Mississauga, Ontario, Canada), and viable cells were identified using the efluor-450, -506 , or -780 fixable viability dye (eBioscience). Lung ILC2s were identified as Lineage-CD45+ $\mathrm{CD} 90.2+\mathrm{CD} 25+\mathrm{Sca} 1+\mathrm{ST} 2+$ viable cells and gated for IL-5 expression based on FMO controls. efluor450-conjugated FoxP3 antibody (FJK-16s) and Foxp3 staining buffer were purchased from eBioscience. The following antibodies for serum immunoglobulin analysis were purchased from BD Pharmingen (Mississauga, Ontario, Canada): HRP-conjugated anti-mouse IgG1 and IgG2a antibodies, and biotin-conjugated anti-mouse IgE and streptavidin-conjugated HRP were obtained from Jackson Immuno Research (West Grove, PA). HDM extract was purchased from Greer Laboratories (Lenoir, NC) and prepared as previously described. ${ }^{28,53}$ Uric acid was detected using an Amplex Red Uric Acid kit as per the manufacturer's directions (Molecular Probes/Invitrogen, Burlington, Ontario, Canada) or the Abcam kit (ab65344) (Abcam, Toronto, Ontario, Canada). Uric acid antibody (AB53000) used previously, ${ }^{28} \mathrm{XDH}$ (AB85541) and MRP4 (AB15602) antibodies were purchased from Abcam and immunohistochemistry reagents were from DAKO (Burlington, Ontario, Canada). LDH assay for cell viability was purchased from Cayman Chemical (Burlington, Ontario, Canada). Influenza $\mathrm{H} 1 \mathrm{~N} 1 \mathrm{~A} / \mathrm{PR} / 8 / 34$ strain and S. pneumoniae serotype 2 (strain d39) were obtained and prepared as described previously. ${ }^{54}$ Bleomycin was purchased from MP Biomedicals (Seven Hills, NSW, Australia). Losartan, indomethacin, IBMX, and forskolin were purchased from Cayman Chemical. The cAMP parameter assay was purchased from R\&D Systems (Mississauga, Ontario, Canada).

Human tissue and in vitro experiments. A minimally immortalized human airway epithelial cell line (HBEC-6KT) was generated from a healthy non-smoker by expression of human telomerase reverse transcriptase and cyclin-dependent kinase 4 (ref. 55) that we have described previously. ${ }^{8,12}$ For human gene expression analysis and basal production of uric acid, primary human airway epithelial cells from healthy donors were isolated from bronchial brushings. Human airway sections were from lungs donated for medical research from the University of British Columbia. For functional experiments, airway epithelial cells were exposed to $50 \mu \mathrm{g}$ of HDM in $1 \mathrm{ml}$ of media for $24 \mathrm{~h}$ followed by uric acid and LDH measurement. MK-571 has been reported to inhibit MRP4 channel activity at $20 \mu \mathrm{M},{ }^{37}$ losartan at $10 \mu \mathrm{M}$, and indomethacin at $10 \mu \mathrm{M}$. Cells were preincubated with antagonists or DMSO diluent for $30 \mathrm{~min}$ before exposure to HDM or media control. For cyclic AMP secretion assays, HBEC-6KT at $80 \%$ confluency was exposed to IBMX $(2 \mu \mathrm{M})$ for $2 \mathrm{~h}$ before exposure to experimental conditions. Following $2 \mathrm{~h}$ IBMX exposure, cells were exposed for $2 \mathrm{~h}$ with MK-571 $(20 \mu \mathrm{M})$ or DMSO control. After these two incubation steps, HBEC-6KT was exposed to forskolin at $10 \mu \mathrm{M}$ with cell-culture supernatants collected $6 \mathrm{~h}$ later for assessment of secreted cyclic AMP.

In vivo experiments. For uricase intervention experiments during $\mathrm{PM}_{10}$ exposure, mice were exposed to a single intranasal dose of $\mathrm{PM}_{10}$ $(200 \mu \mathrm{g})$ or $\mathrm{PM}_{10}(200 \mu \mathrm{g}) /$ uricase $(10 \mathrm{U})$ in $50 \mu \mathrm{l}$ sterile saline, followed by killing $24 \mathrm{~h}$ later. For uric acid analysis studies with HDM, mice were exposed to a single intranasal dose of $100 \mu \mathrm{g}$ per $50 \mu \mathrm{HDM}$ in sterile saline, followed by killing $2 \mathrm{~h}$ later. ${ }^{28}$ For influenza virus exposure, mice were inoculated intranasally with 8 plaque forming unit (p.f.u.) of the mouse-adapted $\mathrm{H} 1 \mathrm{~N} 1$ influenza virus $\mathrm{A} / \mathrm{PR} / 8 / 34$ in $50 \mu \mathrm{l}$ of saline, controls were sham-inoculated with vehicle as described previously. ${ }^{54}$ Mice were killed at 3 days post infection. For $S$. pneumoniae exposure, mice were inoculated with a single intratracheal dose of $2 \times 10^{6}$ p.f.u. in $40 \mu \mathrm{l}$ of saline, followed by killing $8 \mathrm{~h}$ later as described previously. ${ }^{56}$ For bleomycin exposure, mice were administered a single $0.05 \mathrm{U}$ dose of bleomycin sulfate intranasally and killed at various time points. ${ }^{57}$ For OVA alone exposure, mice were administered a single $100 \mu \mathrm{g}$ per $50 \mu \mathrm{l}$ dose, followed by killing $24 \mathrm{~h}$ later. For lipopolysaccharide exposure, mice were administered a $1 \mu \mathrm{g} /$ $50 \mu \mathrm{l}$ dose, followed by killing $24 \mathrm{~h}$ later. For uricase intervention experiments during $\mathrm{PM}_{10}$ and OVA co-exposure, groups of mice were exposed to intranasal saline, OVA $(100 \mu \mathrm{g}) / \mathrm{PM}_{10}(200 \mu \mathrm{g})$, or OVA $(100 \mu \mathrm{g}) / \mathrm{PM}_{10}(200 \mu \mathrm{g}) /$ uricase $(10 \mathrm{U})$ in fixed volumes of $50 \mu \mathrm{l}$ phosphate-buffered saline on days 1,3 , and 5. All groups received intranasal challenge with OVA $(100 \mu \mathrm{g}$ per $50 \mu \mathrm{l})$ on days 21 and 22 , followed by killing $24 \mathrm{~h}$ later. For ILC2 studies, groups of mice were exposed to intranasal saline, OVA $(100 \mu \mathrm{g}) / \mathrm{PM}_{10}(200 \mu \mathrm{g})$, or OVA $(100 \mu \mathrm{g}) / \mathrm{PM}_{10}(200 \mu \mathrm{g}) /$ uricase $(10 \mathrm{U})$ in fixed volumes of $50 \mu \mathrm{l}$ phosphate-buffered saline on days 1, 3, and 5 and killed on day 6. For T-cell proliferation and Treg experiments in an adoptive transfer model, OTII CD4 T cells were isolated from spleens using a magnetic negative CD4 T-cell isolation kit (Stem Cell Technologies, Vancouver, British Columbia, Canada). CD $4+\mathrm{T}$ cells were quantified, CFSE labeled, and tail vein injected into C57BL/6 mice $\left(1.5 \times 10^{6}\right.$ cells per mouse) followed by $24 \mathrm{~h}$ rest. The subsequent day, OTII recipient mice were exposed to intranasal saline, OVA $(100 \mu \mathrm{g}) / \mathrm{PM}_{10}(200 \mu \mathrm{g})$, or OVA $(100 \mu \mathrm{g}) / \mathrm{PM}_{10}(200 \mu \mathrm{g}) /$ uricase $(10 \mathrm{U})$ in $50 \mu \mathrm{l}$ sterile saline. After $48 \mathrm{~h}$ draining mediastinal lymph nodes and control nondraining inguinal lymph nodes were collected for analysis of CD4 $\mathrm{T}$-cell proliferation and quantification of Tregs.

Serum immunoglobulin analysis. Serum OVA-specific IgE, IgG1, and IgG2a were determined by ELISA. Serum dilutions were prepared and antibodies detected using HRP-conjugated anti-mouse IgG1 and IgG2a antibodies and biotin-conjugated anti-mouse IgE. 
Real-time RT-PCR. Lung tissue was stored in RNAlater and homogenized in TRIzol using a TissueLyser II (Qiagen, Toronto, Ontario, Canada). Total RNA was extracted and cDNA was generated using a high capacity cDNA kit (Life Technologies, Mississauga, Ontario, Canada). Quantitative RT-PCR was performed on an ABI 7900HT RT-PCR machine (Applied Biosystems, Burlington, Ontario, Canada) using SYBR Green PCR master mix. Mouse gene expression was normalized to $A c t b$ using the following gene-specific primers: Actb, forward $5^{\prime}$-GGCTGTATTCCCCTCCATCG-3', reverse $5^{\prime}$-CCAGTT GGTAACAATGCCATGT-3'; Il4, forward $5^{\prime}$-TCGGCATTTTGAAC GAGGTC- ${ }^{\prime}$, reverse 5'-CAAGCATGGAGTTTTCCCATG- ${ }^{\prime}$; Il5, forward $5^{\prime}$-GATGAGGCTTCCTGTCCCTACTC- $3^{\prime}$, reverse $5^{\prime}$-TCG CCACACTTCTCTTTTTGG-3'; Il13, forward 5'-CCTGGCTCTTG CTTGCCTT- $3^{\prime}$, reverse $5^{\prime}$-GGTCTTGTGTGATGTTGCTCA-3'; Il33, forward $5^{\prime}$-GGGAAGAAGGTGATGGTGAA- $3^{\prime}$, reverse $5^{\prime}$-CC GAAGGACTTTTTGTGAAGG-3'; Prg2, forward 5' -ATGGGTGACTC TGGATGCAAG- ${ }^{\prime}$, reverse $5^{\prime}$-GCGGACTGGATTCCGAAGT- $3^{\prime}$; $M u c 5 a c$, forward $5^{\prime}$-CAGGACTCTCTGAAATCGTACCA-3', reverse $5^{\prime}$-GAAGGCTCGTACCACAGGG-3' ${ }^{\prime}$, Ifng, forward $5^{\prime}$-GGATGCATTC ATGAGTATTGCC-3', reverse $5^{\prime}$-CCTTTTCCGCTTCCTGAGG-3'; and $T s l p$, forward $5^{\prime}$ TCGAGGACTGTGAGAGCAAGCCAG- ${ }^{\prime}$, reverse $5^{\prime}$-CTGGAGATTGCATGAAGGAATACCA-3'. For human gene expression, the following primers were used MRP4 forward $5^{\prime}$-CAT GGGGAAGACAACCACAGG-3', reverse 5'-ATGGTCCTGATCCTG GCATCC- $3^{\prime}$ and $X D H$ forward $5^{\prime}$-CTGCTCCTTGCACCATGTTGC- ${ }^{\prime}$, reverse $5^{\prime}$-TGGCAATTCTCTCCTGCACAGG-3'.

Statistical analysis. In vivo experiments were repeated in two to three independent trials with each trial having $n=5-10$ for a total of $10-15$ animals. One-way ANOVAs were performed with a post hoc Bonferroni correction for multiple comparisons. A $P$-value of $<0.05$ was accepted to be a statistically significant difference between groups. Data were analyzed using GraphPad Software Version 4.0 (San Diego, CA).

Ethics approval. All human and animal experiments were approved by the University of British Columbia's Office of Research Services Ethics Committee or the University of Newcastle Animal Ethics Committee. For human sample collection, ethics approval and informed consent were obtained.

SUPPLEMENTARY MATERIAL is linked to the online version of the paper at http://www.nature.com/mi

\section{ACKNOWLEDGMENTS}

We acknowledge Dr Vincent from Health Canada for providing $\mathrm{PM}_{10}$ for our experiments. We also acknowledge the Canadian Banting Postdoctoral Fellowship Program, AllerGen Network Centre of Excellence, the Michael Smith Foundation for Health Research, the Canadian Institutes of Health Research, the British Columbia Lung Association, and the National Health and Medical Research Council of Australia for funding this study.

\section{DISCLOSURE}

The authors declared no conflict of interest.

c) 2016 Society for Mucosal Immunology

\section{REFERENCES}

1. Dockery, D.W. et al. An association between air pollution and mortality in six U.S. cities. N. Engl. J. Med. 329, 1753-1759 (1993).

2. McCreanor, J. et al. Respiratory effects of exposure to diesel traffic in persons with asthma. N. Engl. J. Med. 357, 2348-2358 (2007).

3. Diaz-Sanchez, D., Garcia, M.P., Wang, M., Jyrala, M. \& Saxon, A. Nasal challenge with diesel exhaust particles can induce sensitization to a neoallergen in the human mucosa. J. Allergy Clin. Immunol. 104, 1183-1188 (1999).

4. Li, N., Hao, M., Phalen, R.F., Hinds, W.C. \& Nel, A.E. Particulate air pollutants and asthma. A paradigm for the role of oxidative stress in PMinduced adverse health effects. Clin. Immunol. 109, 250-265 (2003).
5. Namork, E., Johansen, B.V. \& Lovik, M. Detection of allergens adsorbed to ambient air particles collected in four European cities. Toxicol. Lett. 165, 71-78 (2006).

6. Vincent, R. et al. Regulation of promoter-CAT stress genes in HepG2 cells by suspensions of particles from ambient air. Fundam. Appl. Toxicol. 39, 18-32 (1997).

7. Heyder, J. Deposition of inhaled particles in the human respiratory tract and consequences for regional targeting in respiratory drug delivery. Proc. Am. Thorac. Soc. 1, 315-320 (2004).

8. Hirota, J.A. et al. The airway epithelium nucleotide-binding domain and leucine-rich repeat protein 3 inflammasome is activated by urban particulate matter. J. Allergy Clin. Immunol. 129, 1116-1125 (2012).

9. Bleck, B., Tse, D.B., Curotto de Lafaille, M.A., Zhang, F. \& Reibman, J. Diesel exhaust particle-exposed human bronchial epithelial cells induce dendritic cell maturation and polarization via thymic stromal lymphopoietin. J. Clin. Immunol. 28, 147-156 (2008).

10. Bleck, B., Tse, D.B., Gordon, T., Ahsan, M.R. \& Reibman, J. Diesel exhaust particle-treated human bronchial epithelial cells upregulate Jagged-1 and OX40 ligand in myeloid dendritic cells via thymic stromal lymphopoietin. J. Immunol. 185, 6636-6645 (2010).

11. Parker, D. \& Prince, A. Innate immunity in the respiratory epithelium. Am. J. Respir. Cell Mol. Biol. 45, 189-201 (2011).

12. Hirota, J.A. et al. The NLRP3 inflammasome/IL-1RI axis mediates innate immune but not adaptive immune responses following PM exposure. Am. J. Respir. Cell Mol. Biol. 52, 96-105 (2015).

13. Li, N. et al. Ambient ultrafine particles provide a strong adjuvant effect in the secondary immune response: implication for traffic-related asthma flares. Am. J. Physiol. Lung Cell. Mol. Physiol. 299, L374-L383 (2010).

14. Li, N. et al. The adjuvant effect of ambient particulate matter is closely reflected by the particulate oxidant potential. Environ. Health Perspect. 117, 1116-1123 (2009).

15. Hirota, J.A. \& Knight, D.A. Human airway epithelial cell innate immunity: relevance to asthma. Curr. Opin. Immunol. 24, 740-746 (2013).

16. Bleck, B. et al. MicroRNA-375 regulation of thymic stromal lymphopoietin by diesel exhaust particles and ambient particulate matter in human bronchial epithelial cells. J. Immunol. 190, 3757-3763 (2013).

17. Vorbach, C., Harrison, R. \& Capecchi, M.R. Xanthine oxidoreductase is central to the evolution and function of the innate immune system. Trends Immunol. 24, 512-517 (2003).

18. Truszkowski, R. \& Goldmanowna, C. Uricase and its action: distribution in various animals. Biochem. J. 27, 612-614 (1933).

19. Orowan, E. The origin of man. Nature 175, 683-684 (1955).

20. Kelly, F.J., Blomberg, A., Frew, A., Holgate, S.T. \& Sandstrom, T. Antioxidant kinetics in lung lavage fluid following exposure of humans to nitrogen dioxide. Am. J. Respir. Crit. Care Med. 154, 1700-1705 (1996).

21. Peden, D.B. et al. Uric acid is a major antioxidant in human nasal airway secretions. Proc. Natl. Acad. Sci. USA 87, 7638-7642 (1990).

22. Hirota, J.A. et al. PM10-stimulated airway epithelial cells activate primary human dendritic cells independent of uric acid: application of an in vitro model system exposing dendritic cells to airway epithelial cell-conditioned media. Respirology 19, 881-890 (2014).

23. Franzoni, F. et al. An in vitro study on the free radical scavenging capacity of ergothioneine: comparison with reduced glutathione, uric acid and trolox. Biomed. Pharmacother. 60, 453-457 (2006).

24. Martinon, F., Petrilli, V., Mayor, A., Tardivel, A. \& Tschopp, J. Goutassociated uric acid crystals activate the NALP3 inflammasome. Nature 440, 237-241 (2006).

25. Ng, G. et al. Receptor-independent, direct membrane binding leads to cellsurface lipid sorting and Syk kinase activation in dendritic cells. Immunity 29, 807-818 (2008).

26. Shi, Y., Evans, J.E. \& Rock, K.L. Molecular identification of a danger signal that alerts the immune system to dying cells. Nature 425, 516-521 (2003).

27. Hammad, H., Chieppa, M., Perros, F., Willart, M.A., Germain, R.N. \& Lambrecht, B.N. House dust mite allergen induces asthma via Toll-like receptor 4 triggering of airway structural cells. Nat. Med. 15, 410-416 (2009).

28. Kool, M. et al. An unexpected role for uric acid as an inducer of T helper 2 cell immunity to inhaled antigens and inflammatory mediator of allergic asthma. Immunity 34, 527-540 (2011). 
29. Hara, K. et al. Airway uric acid is a sensor of inhaled protease allergens and initiates type 2 immune responses in respiratory mucosa. J. Immunol. 192, 4032-4042 (2014).

30. Willart, M.A. et al. Interleukin-1alpha controls allergic sensitization to inhaled house dust mite via the epithelial release of GM-CSF and IL-33. J. Exp. Med. 209, 1505-1517 (2012).

31. Gold, M.J. et al. Group 2 innate lymphoid cells facilitate sensitization to local, but not systemic, TH2-inducing allergen exposures. J. Allergy Clin. Immunol. 133, 1142-1148 (2014).

32. Webb, R., Jeffries, M. \& Sawalha, A.H. Uric acid directly promotes human T-cell activation. Am. J. Med. Sci. 337, 23-27 (2009).

33. Coombes, J.L. et al. A functionally specialized population of mucosal CD103 + DCs induces Foxp3 + regulatory T cells via a TGF-beta and retinoic acid-dependent mechanism. J. Exp. Med. 204, 1757-1764 (2007).

34. Hediger, M.A., Johnson, R.J., Miyazaki, H. \& Endou, H. Molecular physiology of urate transport. Physiology (Bethesda) 20, 125-133 (2005).

35. Vincent, R. et al. Acute pulmonary toxicity of urban particulate matter and ozone. Am. J. Pathol. 151, 1563-1570 (1997).

36. Sevanian, A., Davies, K.J. \& Hochstein, P. Serum urate as an antioxidant for ascorbic acid. Am. J. Clin. Nutr. 54, 1129S-1134S (1991).

37. Conner, G.E., Ivonnet, P., Gelin, M., Whitney, P. \& Salathe, M. HO stimulates CFTR through an autocrine prostaglandin pathway using MRP4. Am. J. Respir. Cell Mol. Biol. 49, 672-679 (2013).

38. Russel, F.G., Koenderink, J.B. \& Masereeuw, R. Multidrug resistance protein 4 (MRP4/ABCC4): a versatile efflux transporter for drugs and signalling molecules. Trends Pharmacol. Sci. 29, 200-207 (2008).

39. Ullah, M.A. et al. Receptor for advanced glycation end products and its ligand high-mobility group box-1 mediate allergic airway sensitization and airway inflammation. J. Allergy Clin. Immunol. 134, 440-450 (2014).

40. Herold, S., Ludwig, S., Pleschka, S. \& Wolff, T. Apoptosis signaling in influenza virus propagation, innate host defense, and lung injury. J. Leukoc. Biol. 92, 75-82 (2012).

41. Hoshino, Y., Mio, T., Nagai, S., Miki, H., Ito, I. \& Izumi, T. Cytotoxic effects of cigarette smoke extract on an alveolar type II cell-derived cell line. Am. J. Physiol. Lung Cell. Mol. Physiol. 281, L509-L516 (2001).

42. D’Agostini, F., Balansky, R.M., Izzotti, A., Lubet, R.A., Kelloff, G.J. \& De Flora, S. Modulation of apoptosis by cigarette smoke and cancer chemopreventive agents in the respiratory tract of rats. Carcinogenesis 22 , 375-380 (2001).
43. Lee, V.Y. et al. Bleomycin induces alveolar epithelial cell death through JNK-dependent activation of the mitochondrial death pathway. Am. J. Physiol. Lung Cell. Mol. Physiol. 289, L521-L528 (2005).

44. Schmeck, B. et al. Streptococcus pneumoniae-induced caspase 6-dependent apoptosis in lung epithelium. Infect. Immun. 72, 4940-4947 (2004).

45. Shi, Y., Mucsi, A.D. \& Ng, G. Monosodium urate crystals in inflammation and immunity. Immunol. Rev. 233, 203-217 (2010).

46. Allen, K.C. et al. Risk of anaphylaxis with repeated courses of rasburicase: a Research on Adverse Drug Events and Reports (RADAR) Project. Drug Saf. 38, 183-187 (2015).

47. Gasse, P. et al. Uric acid is a danger signal activating NALP3 inflammasome in lung injury inflammation and fibrosis. Am. J. Respir. Crit. Care Med. 179, 903-913 (2009).

48. Kuipers, M.T. et al. Pre-treatment with allopurinol or uricase attenuates barrier dysfunction but not inflammation during murine ventilator-induced lung injury. PLoS One 2012)7, e50559.

49. Savoca, K.V., Davis, F.F. \& Palczuk, N.C. Induction of tolerance in mice by uricase and monomethoxypolyethylene glycol-modified uricase. Int. Arch. Allergy Appl. Immunol. 75, 58-67 (1984).

50. Furuhashi, K. et al. Mouse lung CD103 + and CD11bhigh dendritic cells preferentially induce distinct CD4 + T-cell responses. Am. J. Respir. Cell Mol. Biol. 46, 165-172 (2012).

51. Plantinga, M. et al. Conventional and monocyte-derived CD11b $(+)$ dendritic cells initiate and maintain $\mathrm{T}$ helper 2 cell-mediated immunity to house dust mite allergen. Immunity 38, 322-335 (2013).

52. So, A. \& Thorens, B. Uric acid transport and disease. J. Clin. Invest. 120, 1791-1799 (2010).

53. Hirota, J.A. et al. The role of interleukin-4Ralpha in the induction of glutamic acid decarboxylase in airway epithelium following acute house dust mite exposure. Clin. Exp. Allergy 40, 820-830 (2010).

54. Beckett, E.L. et al. A new short-term mouse model of chronic obstructive pulmonary disease identifies a role for mast cell tryptase in pathogenesis. J. Allergy Clin. Immunol. 131, 752-762 (2013).

55. Ramirez, R.D. et al. Immortalization of human bronchial epithelial cells in the absence of viral oncoproteins. Cancer Res. 64, 9027-9034 (2004).

56. Preston, J.A. et al. Streptococcus pneumoniae infection suppresses allergic airways disease by inducing regulatory T-cells. Eur. Respir. J. 37, 53-64 (2011).

57. O'Donoghue, R.J. et al. Genetic partitioning of interleukin-6 signalling in mice dissociates Stat3 from Smad3-mediated lung fibrosis. EMBO Mol. Med. 4, 939-951 (2012). 